
\title{
25 Research Soure \\ Effect of Body Mass Index on the outcomes of primary Total Knee Arthroplasty up to one year- a prospective cohort study
}

Ashish Kumar Mishra ( $\square$ am460981@gmail.com )

Indraprastha Apollo Hospitals

Abhishek Vaish

Indraprastha Apollo Hospitals

Raju Vaishya

Indraprastha Apollo Hospitals

\section{Research Article}

Keywords: Total Knee Arthroplasty, Obesity, Body Mass Index, Osteoarthritis, Infection

Posted Date: August 23rd, 2021

DOl: https://doi.org/10.21203/rs.3.rs-829103/v1

License: (c) (i) This work is licensed under a Creative Commons Attribution 4.0 International License. Read Full License

Version of Record: A version of this preprint was published at Journal of Clinical Orthopaedics and Trauma on March 1st, 2022. See the published version at https://doi.org/10.1016/j.jcot.2022.101829. 


\section{Abstract \\ Background}

Obesity is an important risk factor in development of knee osteoarthritis, and these cases suffer from complications following Total Knee Arthroplasty (TKA). The association between obesity and outcomes after TKA is ambiguous. Knowledge is scarce about a definite relation between the two. This study aims to establish a correlation between obesity and early outcomes of TKA.

\section{Methods}

This prospective cross-sectional study was done in cases undergoing primary knee arthroplasty between September 2019 to August 2020. Obesity was classified in all cases, and multiple variables like pain, functional status, Range of Motion, knee deformity, and Patient Response Outcome Measures were recorded. Statistical analysis was performed using SPSS Statistical Software version 22.0 and R.3.2.0. The level of statistical significance was taken as $p<0.05$.

\section{Results}

We studied 100 knees (37 bilateral and 26 unilateral) in 63 cases. Pain score decreased maximally in the normal and overweight group and minimal in class III obesity $(p<0.001)$. KSS, FKSS, and PROMs gradually improved in all, except in morbidly obese $(p<0.001)$. Although the improvement in all variables was minimum in class III obesity compared to other classes of obesity, the margin of difference from the preoperative period was maximum in class III obese participants.

\section{Conclusion}

All cases, irrespective of class of obesity, experienced a comparable improvement in their knee function and improved quality of life. In addition, the TKA offered substantial benefits in terms of range of movement of the knee, pain relief, knee stability, walking distance, and stairs climbing.

\section{Introduction}

According to World Health Organization (WHO), obesity is a medical condition that can be quantified by the Body Mass Index (BMI) and is closely related to total body fat percentages. The WHO has classified obesity according to the BMI into four grades- Grade I- Overweight (BMI- 25.0-29.9), Grade II- Class I Obesity (BMI30-34.9), Grade III- Class II Obesity (BMI-35.0-39.9), and Grade IV- Class III Obesity (BMI > 40) [1].

Obesity is a significant risk factor for developing knee osteoarthritis (OA), with a three- to five-fold increased risk compared with normal patients [2-4]. Obese individuals are more prone to develop knee OA in early life and suffer from complications following Total Knee Arthroplasty (TKA) [5, 6]. The risk of developing OA 
increases by $36 \%$ for every 5-kilo gram increase in BMI [7]. Although for patients with severe knee OA, TKA is the most effective treatment [8], obese patients are considered poor candidates for TKA. Higher BMI is associated with limitation in physical performance and functional mobility in elderly or patients with severe $\mathrm{OA}$ and associated with post-TKA physical disability [9]. The BMI of cases needing TKA has increased over time, and the corelation between high BMI and the risk of subsequent TKA has become a focus for research [10].

The association between knee $\mathrm{OA}$ and obesity is recognized for several years. However, the relationship between obesity and outcomes after TKA is ambiguous. There is still a scarcity of knowledge in the literature about a definite relation between the two. This study aims to establish a correlation between obesity and early outcomes of TKA.

\section{Material And Methods}

After taking an institutional ethical clearance, a prospective, observational, cross-sectional study was done in patients undergoing primary TKA for one year (September 2019-August 2020) at a tertiary care hospital. We included all moderate to severe knee OA cases undergoing TKA. The knees with inflammatory arthritis and any prior surgical interventions (e.g., arthroscopic surgery, corrective osteotomy, etc.) were excluded.

All the participants were classified as per their BMI (according to WHO classification), and multiple variables like pain, functional status, Range of Motion (ROM), Deformity of the knee, and Patient Response Outcome Measures (PROMs) were recorded pre-operatively. In addition, the pain was assessed by Visual Analog Scale (VAS), Functional status was assessed by Knee Society Score (KSS), and Functional Knee Society Score (FKSS).

Postoperatively assessment was done for the pre-operatively recorded variables and postoperative complications on four time periods- A) Immediate (Day1-Day10), B) intermediate (Day10-6 weeks), C) late (6weeks to 6 months), and D) final (6months-1year) following the index surgery.

Statistical analysis was performed using SPSS Statistical Software version 22.0 and R.3.2.0. Clinical Parameters were presented in Frequency (\%) for qualitative variables and Mean and Standard Deviation (SD) for quantitative variables. Wilcoxon Rank-Sum Test was applied to compare the clinical parameters like Blood loss, Length of Stay between groups of patients (Group-1: BMI <30, Group-2: BMI > 30). Wilcoxon Signed-Rank test was used to compare parameters at different follow-ups. The level of statistical significance was taken as $p<0.05$.

\section{Results}

A total of 152 knees in 100 patients were initially screened for this study. We excluded 37 patients (52 knees) who did not meet the inclusion criteria. Thus, 63 patients with 100 knees (37 bilateral and 26 unilateral) were assessed in the study. Out of 100 knees, distribution in various categories of obesity was normal (4), overweight (18), class I (30), class II (46), and class III (2). 
A transition to a higher class of obesity was associated with poorer outcomes. Pain score gradually decreased with time in all the classes of obesity (Table-1), with maximum decrease in a normal and overweight and minimum decrease in class III obesity $(p<0.001)$. KSS and FKSS gradually improved with time in all classes (Table-1), with morbidly obese patients having a minor improvement $(p<0.001)$. The PROMs were better in all classes of obesity (Table-2), as compared to the preoperative condition and class III obesity had the least satisfactory PROMs $(p<0.001)$.

With the increase in the class of obesity, the time taken for mobilization and length of stay in hospital was prolonged, blood loss and need for transfusion increased. On the other hand, time taken to return to activity of daily life and ROM to the normal range was maximum in class III obesity (Table-3), $[p<0.001]$.

During the final follow-up, all classes of obesity had similar functional outcomes with no residual deformity, and PROMs also were identical (Table-4), [p < 0.001]. Although the improvement in all variables was minimum in class III obesity compared to other classes of obesity, the margin of difference from the preoperative period was maximum in class III obese participants. Patient satisfaction after surgery and improvement in quality of life was also maximum in class III.

\section{Discussion}

The association between BMI and outcomes of TKA is unclear. Some studies have shown an increase in $\mathrm{BMI}$ had negative effect on the results, whereas the others showed no relationship between BMI and the outcomes. Pasquier et al. reported presence of varus deformity and morbid obesity resulted in a greater gain in flexion postoperatively. Although, the final flexion was lower than the mean in the overall population [11]. We noticed that the difference of preoperative and final flexion achieved was maximum in class III obesity (Table 1 ).

Singh et al. found that BMI had no effect on the postoperative joint perception, and all classes of obesity experienced similar functional outcomes following TKA [12]. We noticed a difference in the functional outcome in the immediate, intermediate, and late postoperative period but the final functional outcome after one year from the surgery was the same in all obesity classes (Table 4 and Fig. 1). The cases with a higher BMI are at increased risk of attaining lower functional scores following TKA [13]. Similarly, the maximum improvement in functional scores with the least incidence of infection was seen in a normal and overweight group. In contrast, minimum improvement in functional scores with the highest incidence of infection was seen in the morbidly obese group. The trend of decrease in the final functional score was seen while going up in the categories of obesity (Table 1 and Table 3).

It is documented that the obese patient had an increased risk of medical and surgical complications with an increase in rates of complications with an increase in the class of obesity [14]. We observed that all the perioperative complications were maximum in the morbidly obese group and were minimum in the normal or overweight group. The risk of developing complications increased with a transition to higher classes of obesity (Table 3 ). 
An adverse effect of obesity on implant survival is often debated. Gaillard et al. reported that obesity had no effect on mid-term implant survival, though their results showed poor functional outcomes in the obese [15]. We also noticed that the implant positioning, radio-lucent lines around the implants, and implant survival at one year did not correlate with the grades of BMI or classes of obesity. It is a common belief that overloading of the knee occurs with increase in BMI causing more significant loading across the tibial component resulting in poor implant survival $[16,17,18]$. Despite this, it is found that a more sedentary lifestyle in morbidly obese patients counters implant's wear.

Our mean preoperative and postoperative overall KSS and FKSS were consistently lower in Class III obesity, although the difference between the two was maximum in class III obesity. Chen et al. studied 117 morbidly obese and 2108 non-obese patients, FKSS between the two groups was comparable and improvement in KSS was superior in obese patients [19]. However, our final KSS and the FKSS were similar in all classes of obesity. Krushell et al. found the minimum improvement in FKSS of 13 in the morbidly obese (class III obesity) vs. 26 in the non-obese group [20]. Their results signify that a morbidly obese patient who was housebound earlier can now walk for a significant distance postoperatively.

We were lucky not to encounter any postoperative infections in our subjects in the immediate postoperative period and up to the first year of their follow-up. However, these patients need to be closely observed in the future for any delayed complications like prosthetic joint infections and implant loosening. We suggest that the morbid obesity group not be denied TKA based on their BMI solely, as the procedure significantly improves functional capability and quality of life [21].

\section{Limitations}

We acknowledge some limitations of this study. The sample size was not huge, and it was a single-center study. In addition, the follow-up period was up to one year, which is short for assessing the long-term complications and survival of a TKA. However, the study describes the early clinical outcomes, up to one year, in obese cases, considered high-risk individuals.

\section{Conclusion}

All cases, irrespective of class of obesity, experienced a comparable improvement in their knee function and improved quality of life. In addition, the TKA in our cohort offered substantial benefits in terms of walking distance, pain relief, range of movement of the knee, knee stability, and stairs climbing.

\section{Declarations}

\section{Conflict of interest-}

None

\section{References}


1. Zierle-Ghosh A, Jan A. Physiology, Body Mass Index. [Updated 2020 Jul 26]. In: Stat Pearls [Internet]. Treasure Island (FL): Stat Pearls Publishing; 2021 Jan-.

2. Salih S, Sutton P. Obesity, knee osteoarthritis and knee arthroplasty: a review. BMC Sports Sci Med Rehabil. 2013 Dec 4;5(1):25. doi: 10.1186/2052-1847-5-25. PMID: 24304704; PMCID: PMC3879025.

3. Blagojevic M, Jinks C, Jeffery A, Jordan KP. Risk factors for onset of osteoarthritis of the knee in older adults: a systematic review and meta-analysis. Osteoarthritis Cartilage. 2010 Jan;18(1):24-33. doi: 10.1016/j.joca.2009.08.010. E pub 2009 Sep 2. PMID: 19751691.

4. Odum SM, Springer BD, Dennos AC, Fehring TK. National obesity trends in total knee arthroplasty. J Arthroplasty. 2013 Sep;28(8 Suppl):148 - 51. doi: 10.1016/j.arth.2013.02.036. E pub 2013 Aug 15. PMID: 23953395.

5. Sturmer T, Günther KP, Brenner H. Obesity, overweight and patterns of osteoarthritis: the Ulm Osteoarthritis Study. J Clin Epidemiol. 2000 Mar 1;53(3):307 - 13. doi: 10.1016/s08954356(99)00162-6. PMID: 10760642.

6. Friedman RJ, Hess S, Berkowitz SD, Homering M. Complication rates after hip or knee arthroplasty in morbidly obese patients. Clin Orthop Relat Res. 2013 Oct;471(10):3358-66. doi: 10.1007/s11999-0133049-9. Epub 2013 May 14. PMID: 23670675; PMCID: PMC3773108.

7. Wendelboe AM, Hegmann KT, Biggs JJ, Cox CM, Portmann AJ, Gildea JH, Gren LH, Lyon JL. Relationships between body mass indices and surgical replacements of knee and hip joints. Am J Prev Med. 2003 Nov;25(4):290-5. doi: 10.1016/s0749-3797(03)00218-6. PMID: 14580629.

8. Robbins CE, Bono JV, Ward DM, Barry MT, Doren J, McNinch A. Effect of preoperative exercise on postoperative mobility in obese total joint replacement patients. Orthopedics. 2010 Sep 7;33(9):666. doi: 10.3928/01477447-20100722-09. PMID: 20839706.

9. Marcus RL, Yoshida Y, Meier W, Peters C, Lastayo PC. An Eccentrically Biased Rehabilitation Program Early after TKA Surgery. Arthritis. 2011; 2011:353149. doi: 10.1155/2011/353149. Epub 2011 Apr 7. PMID: 22046514; PMCID: PMC3195282.

10. Naylor JM, Harmer AR, Heard RC. Severe other joint disease and obesity independently influence recovery after joint replacement surgery: an observational study. Aust J Physiother. 2008;54(1):57-64. doi: 10.1016/s0004-9514(08)70067-9. PMID: 18298360.

11. Pasquier G, Tillie B, Parratte S, Catonné Y, Chouteau J, Deschamps G, Argenson JN, Bercovy M, Salleron J. Influence of preoperative factors on the gain in flexion after total knee arthroplasty. Orthop Traumatol Surg Res. 2015 Oct;101(6):681-5. doi: 10.1016/j.otsr.2015.06.008. Epub 2015 Sep 18. PMID: 26388543.

12. Singh V, Yeroushalmi D, Lygrisse KA, Simcox T, Long WJ, Schwarzkopf R. The influence of obesity on achievement of a 'forgotten joint' following total knee arthroplasty. Arch Orthop Trauma Surg. 2021 Mar 4. doi: 10.1007/s00402-021-03840-0. Epub ahead of print. PMID: 33661386.

13. Si HB, Zeng Y, Shen B, Yang J, Zhou ZK, Kang PD, Pei FX. The influence of body mass index on the outcomes of primary total knee arthroplasty. Knee Surg Sports Traumatol Arthrosc. 2015 Jun;23(6):1824-32. doi: 10.1007/s00167-014-3301-1. Epub 2014 Sep 13. PMID: 25217315. 
14. Zusmanovich M, Kester BS, Schwarzkopf R. Postoperative Complications of Total Joint Arthroplasty in Obese Patients Stratified by BMI. J Arthroplasty. 2018 Mar,33(3):856-864. doi: 10.1016/j.arth.2017.09.067. Epub 2017 Oct 10. PMID: 29089223.

15. Gaillard R, Gaillard T, Denjean S, Lustig S. No influence of obesity on survival of cementless, posteriorstabilised, rotating-platform implants. Arch Orthop Trauma Surg. 2017 Dec;137(12):1743-1750. doi: 10.1007/s00402-017-2801-0. Epub 2017 Sep 22. PMID: 28939967.

16. Amin AK, Clayton RA, Patton JT, Gaston M, Cook RE, Brenkel IJ. Total knee replacement in morbidly obese patients. Results of a prospective, matched study. J Bone Joint Surg Br. 2006 Oct;88(10):1321-6. doi: 10.1302/0301-620X.88B10.17697. PMID: 17012421.

17. Naziri Q, Issa K, Malkani AL, Bonutti PM, Harwin SF, Mont MA. Bariatric orthopaedics: total knee arthroplasty in super-obese patients (BMI > $50 \mathrm{~kg} / \mathrm{m} 2)$. Survivorship and complications. Clin Orthop Relat Res. 2013 Nov;471(11):3523-30. doi: 10.1007/s11999-013-3154-9. Epub 2013 Jul 10. PMID: 23839328; PMCID: PMC3792257.

18. Gunst S, Fessy MH. The effect of obesity on mechanical failure after total knee arthroplasty. Ann Transl Med. 2015 Nov;3(20):310. doi: 10.3978/j.issn.2305-5839.2015.10.37. PMID: 26697470; PMCID: PMC4669315.

19. Chen JY, Lo NN, Chong HC, Bin Abd Razak HR, Pang HN, Tay DK, Chia SL, Yeo SJ. The influence of body mass index on functional outcome and quality of life after total knee arthroplasty. Bone Joint $\mathrm{J}$. 2016 Jun;98-B(6):780-5. doi: 10.1302/0301-620X.98B6.35709. PMID: 27235520.

20. Krushell RJ, Fingeroth RJ. Primary Total Knee Arthroplasty in Morbidly Obese Patients: a 5- to 14-year follow-up study. J Arthroplasty. 2007 Sep;22(6 Suppl 2):77-80. doi: 10.1016/j.arth.2007.03.024. Epub 2007 Jul 26. PMID: 17823021.

21. Vaishya R, Vijay V, Wamae D, Agarwal AK. Is Total Knee Replacement Justified in the Morbidly Obese? A Systematic Review. Cureus. 2016 Sep 23;8(9):e804. doi: 10.7759/cureus.804. PMID: 27790392; PMCID: PMC5081255.

\section{Tables}

\section{TABLE 1- COMPARISON OF DIFFERENT CLASSES OF OBESITY WITH PAIN SCORE, KNEE SOCIETY SCORE AND PATIENT FUNCTION SCORE}


A) PAIN SCORE CLASS $1 \quad \begin{array}{llll}\text { CLASS } & \text { CLASS NORMAL OVERWEIGHT } & \text { p-value }\end{array}$

\begin{tabular}{|c|c|c|c|c|c|c|c|c|}
\hline PRE-OP & 7.7 & 7.9 & 9 & & 6.5 & 7.2 & & $<0.001$ \\
\hline IMMEDIATE & 4.2 & 3.8 & 6 & & 3 & 4 & & $<0.001$ \\
\hline INTERMEDIATE & 2.4 & 2.0 & 4 & & 2 & 2.3 & & $<0.001$ \\
\hline LATE & 0.8 & 2 & 3 & & 0 & 1.1 & & $<0.001$ \\
\hline FINAL & 0 & 0 & 2 & & 0 & 0 & & $<0.001$ \\
\hline \multicolumn{9}{|l|}{$\begin{array}{l}\text { B) KNEE } \\
\text { SOCIETY } \\
\text { SCORE }\end{array}$} \\
\hline PRE-OP & 47.7 & 49.2 & & 43 & 49.2 & & 44.5 & $<0.001$ \\
\hline IMMEDIATE & 70.8 & 71.5 & & 68 & 72 & & 68.1 & $<0.001$ \\
\hline INTERMEDIATE & 72.7 & 72.7 & & 68.5 & 77.5 & & 73.2 & $<0.001$ \\
\hline LATE & 82.8 & 82.8 & & 72 & 83 & & 80.8 & $<0.001$ \\
\hline FINAL & 88.6 & 88.4 & & 82 & 88.7 & & 87.7 & $<0.001$ \\
\hline \multicolumn{9}{|c|}{$\begin{array}{l}\text { C) PATIENT FUNCTION } \\
\text { SCORE }\end{array}$} \\
\hline PRE-OP & 24.5 & 28.2 & & 55 & 55 & & 31.9 & $<0.001$ \\
\hline IMMEDIATE & 40 & 30 & & 25 & 25 & & 30 & $<0.001$ \\
\hline INTERMEDIATE & 72.8 & 55 & & 55 & 55 & & 55 & $<0.001$ \\
\hline LATE & 77.3 & 72.9 & & 75 & 75 & & 71.6 & $<0.001$ \\
\hline FINAL & 80 & 80 & & 80 & 80 & & 80 & $<0.001$ \\
\hline
\end{tabular}

TABLE 2- COMPARISON OF DIFFERENT CLASSES OF OBESITY WITH PATIENT RESPONSE OUTCOME:

PATIENT RESPONSE OUTCOME

\begin{tabular}{lllllll} 
PRE-OP & 52.1 & 53.5 & 59 & 54 & 52.2 & $<0.001$ \\
\hline LATE & 27 & 27.4 & 31 & 24 & 22.7 & $<0.001$ \\
\hline FINAL & 19.8 & 20 & 23 & 20 & 19 & $<0.001$
\end{tabular}


TABLE 3- COMPARISON OF DIFFERENT CLASSES OF OBESITY WITH IMMEDIATE AND INTERMEDIATE OUTCOMES

A) IMMEDIATE (POST OP

DAY 1-DAY10)

CLASS CLASS CLASS NORMAL OVERWEIGHT p-

$\begin{array}{llll}1 & 2 & 3 & \text { value }\end{array}$

MOBILISATION (in days)

LENGTH OF HOSPITAL

STAY (in days)

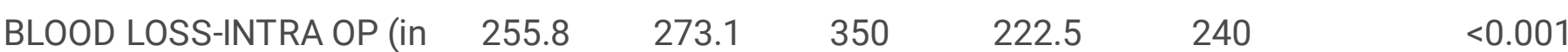
$\mathrm{ml}$ )

$\begin{array}{lllllll}\text { BLOOD LOSS-POST OP (in } & 157.5 & 177.3 & 285 & 85 & 117.8 & <0.001\end{array}$ $\mathrm{ml})$

$1.5 \quad 2$

2.5

1.11

$<0.001$

$4.11<0.001$

$4-4$

54

$4 \quad 4.11$

B) INTERMEDIATE (POST OP DAY

11- 6 WEEKS)

RETURN TO DAILY ACTIVITY (in weeks)

ROM TO NORMAL (in weeks) $\begin{array}{lll}4 & 4.04 & 6\end{array}$

$\begin{array}{lll}4 & 4 & 6\end{array}$

3

6

3.2
3.72

4
$<0.001$

$<0.001$

\section{TABLE 4- COMPARISON OF DIFFERENT CLASSES OF OBESITY WITH LATE AND FINAL OUTCOMES}

\begin{tabular}{lllllll}
$\begin{array}{l}\text { A) LATE (6 WEEK TO } 6 \\
\text { MONTH) }\end{array}$ & $\begin{array}{l}\text { CLASS } \\
1\end{array}$ & $\begin{array}{l}\text { CLASS } \\
2\end{array}$ & $\begin{array}{l}\text { CLASS } \\
3\end{array}$ & NORMAL & OVERWEIGHT & $\begin{array}{l}\text { p- } \\
\text { value }\end{array}$ \\
\hline FUNCTIONAL OUTCOMES & 77.3 & 72.9 & 75 & 75 & 71.6 & $<0.001$ \\
\hline PROMS & 27 & 23 & 27 & 24 & 22.7 & $<0.001$ \\
\hline $\begin{array}{l}\text { B) FINAL FOLLOW-UP }(1 \\
\text { YEAR) }\end{array}$ & & & & & & \\
$\begin{array}{l}\text { FUNCTIONAL OUTCOMES } \\
\text { PROMS }\end{array}$ & 80 & 80 & 80 & 80 & 80 & $<0.001$ \\
\hline
\end{tabular}

\section{Figures}




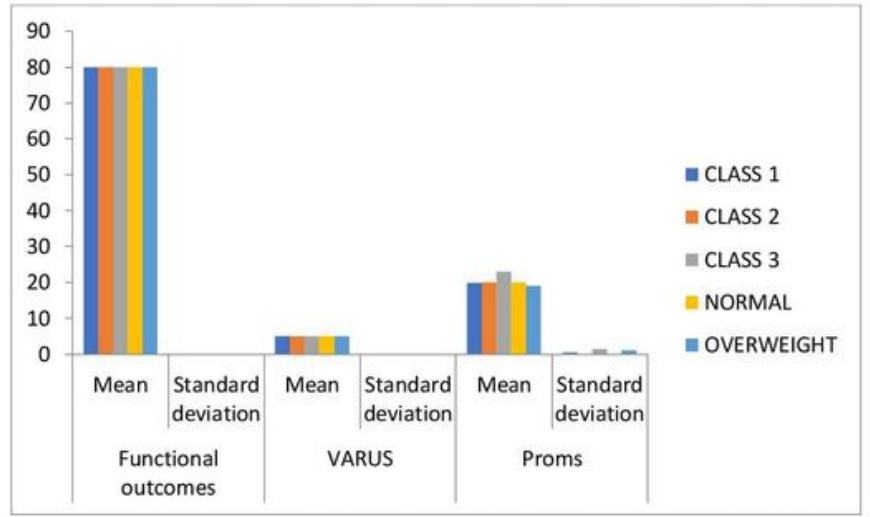

FIGURE 1- COMPARISON OF CLASSES OF OBESITY WITH THE FINAL OUTCOMES OF TKA

Figure 1

Comparison of classes of obesity with the final outcomes of TKA 